\title{
Suicide: Posthumous Notes Analysis from Inhabitants of Mexico City
}

\author{
María de la Luz Sevilla González ${ }^{{ }^{*}}$, Nelli G. Rodríguez Diaz ${ }^{2}$, Nelson E. Alvarez Licona \\ ${ }^{1}$ Higher School of Medicine, Instituto Politécnico Nacional, Mexico City, Mexico \\ ${ }^{2}$ Specialty Forensic Medicine, Instituto Politécnico Nacional, Mexico City, Mexico \\ Email: *msevillag@ipn.mx
}

How to cite this paper: Sevilla González, M. L., Rodríguez Diaz, N. G., \& Alvarez Licona, N. E. (2020). Suicide: Posthumous Notes Analysis from Inhabitants of Mexico City. Advances in Anthropology, 10, 275-282. https://doi.org/10.4236/aa.2020.104015

Received: September 4, 2020

Accepted: November 27, 2020

Published: November 30, 2020

Copyright $\odot 2020$ by author(s) and Scientific Research Publishing Inc. This work is licensed under the Creative Commons Attribution International License (CC BY 4.0).

http://creativecommons.org/licenses/by/4.0/

\begin{abstract}
The research results presented here correspond to 5 years of continuous work, focused on the methodology of Discourse Analysis, based on the analysis of content articulated to the work of forensic medicine. The sample focused on the analysis of posthumous messages, of people who committed suicide by hanging. This line of study was carried out at the National Polytechnic Institute (Key SIP Project: No 20181294) carried out at INCIFO in Mexico City. The results rest on the use of a nonparametric test for difference in proportions as well as summary measures such as ratio, proportion, and percentage. What it was found was that the most frequent motivation was sentimental ( $52 \%$ men, $45 \%$ women) followed by guilt ( $27 \%$ women, $5 \%$ men). The receiver of the message, in the first place, was the couple $33 \%$ men, $20 \%$ women), and in second place the parents (10\% women and $19 \%$ men). Regarding occupation, the ones that have the highest rates of suicide were employees ( $48 \%)$, and police officers (34\%). Finally, the district with the highest rate of suicides was Iztapalapa ( $30 \%$ women and $24 \%$ men) within the winter months of January and February (98\% and 100\%) respectively in the total of deaths.
\end{abstract}

\section{Keywords}

Posthumous Note, Suicide, Forensic Linguistic Analysis, Content Analysis, Motives

\section{Introduction}

Globally, there are approximately one million suicides per year. The World Health Organization (WHO, 2020) has classified this natural phenomenon as a severe public health problem since "the global death rate" is 16 for every 100,000 , i.e., one death every 40 seconds (OMS, 2020). The suicide phenomenon 
is shocking in all the continents. The WHO has registered that in the last 45 years, the suicide rates have increased $60 \%$ globally.

In the United States, suicide ranks the 10th in the causes of death, reporting 48,000 cases of deceased persons in 2018. Regarding age group, suicide is one of the three main causes of death among people between the ages of 15 and 44 . According to international research, in Mexico, the yearly average of suicides was 6,377 from 2014 to 2016; 14\% higher than the previous period of 2010 and 2014 whose figure was 5,547 annually. Between 2010 and 2016, the figures reached a total of 41,321 suicides. The states with the highest suicide rates are Chihuahua, Yucatan, Aguascalientes, Campeche, and Colima (INEGI, 2020). In Mexico, people aged from 15 to 24 years are the group with more suicide prevalence. Suicide is defined as the death produced by oneself with the purpose of ending his/her life (Durkheim, 1995). There are a lot of reasons that lead and encourage to suicide, though most of them are not very clear. The intent of the act is overshadowed by an unclear forensic analysis; in other words, there are some cases where the diagnosis is difficult to determine whether it is a suicide, an accident, or a homicide.

Suicide has been studied globally and from different perspectives, disciplines, and methodologies. This research aims to show results based on quantitative and qualitative methodologies applied in the suicide phenomenon. The analysis of the posthumous notes content (González, 2014) is a methodology that creates sensitive and valuable results. The academics that participated in this research are doctors, anthropologists, sociolinguistics, and experts in forensics. It is important to mention that this study had the difficulty of obtaining posthumous notes (the family: keeps them, hides them, or destroys them) without considering that they are valuable evidence. Moreover, it is noteworthy that all the research related to suicide must be taken into account. More importantly, it is necessary to sensitize family members and authorities of the Public Ministry in Mexico, and the National Institute of Forensic Sciences, so that they facilitate access to this information in order to carry out more research and generate prevention programs. Furthermore, the results from the information analysis can be useful to develop treatment programs necessary for this increasing social phenomenon whose social cost is human lives. The truth is that suicide is a taboo subject that is not socially discussed, and the relatives are clouded and silent due to the pain of their experience. There are a few cases, even none, where relatives of the subject overcome their grief, thereby affecting others' lives. The family may also be an obstacle to getting information about the motives that led to the outcome. There is no doubt that the explicit and implicit language in the obtained premortem notes represents an opportunity to clarify the situation of the subject before $\mathrm{s} / \mathrm{he}$ made the decision, his/her emotional state or anxiety $\mathrm{s} / \mathrm{he}$ suffered, as well as the meaning and the direction of the suicide. The obtained results show relevant and useful information to doctors, forensic clinicians, psychologists, psychiatrists, anthropologists, and social workers who can develop treatment programs for subjects at risk. 
Prior to the results presented here, a previous investigation was developed in 2015 called, "Premortem letter: The last speech of a suicide by means of cluster analysis (Juárez, 2015)" This research opens a watershed to work on discourse analysis methodologies applied to the forensic analysis of premortem notes. The research articulates sociolinguistics and forensic medicine (Nely Rodríguez, 2019). Subsequently, in 2019, the research: Motivation of suicide expressed in posthumous messages in people by hanging in Mexico City was carried out; this study was developed in the archives of INCIFO to whom we give special thanks for the support provided. And finally, in 2020, a study was carried out called: Identification of factors linked to suicide and its correlation with psychosocial and academic variables in IPN Medicine students (Román, 2020). These three investigations were developed at the Instituto Politécnico Nacional (González, 2020) at the Higher School of Medicine, Human Behavior Laboratory Area under the direction of Dr. María de la Luz Sevilla González.

\section{Methodology}

In order to achieve the objectives, a text analysis study was designed. This study was observational and retrospective. 500 cases, classified as death by suicide, were reviewed in the Institute of Forensic Sciences in Mexico City (INCIFO). The only analyzed cases were the ones of suicide by hanging, with posthumous notes: coherent, legible, and longer than a phrase. It did not matter whether the note was written on a sheet of paper, on the mirror, on the wall, on the floor, etc. Among all the analyzed cases, 31 posthumous notes were found and analyzed in two stages: In the first study stage, a behavioral descriptive analysis was carried out. This analysis was based on dichotomous ordinal qualitative Variables. 1) gender, 2) background, 3) receiver; and polytomous ordinal qualitative Variables. 4) marital status, 5) occupation, 6) motivation, 7) level of education, 8) religion, 9) month of the suicide, 10) place, 11) district.

In the second study stage, implicit information from the premortem notes was analyzed with an Automatic Discourse (González, 2010) Analysis (ADA) in which 8 variables or discursive objects were studied: 1) guilt, 2) farewell and thankfulness, 3) money, 4) anger, wrath, sadness, and meaninglessness, 5) spirituality, 6) instructions, 7) forgiveness, 8) clarification.

The annual average nationwide in the number of suicides, between 2014 and 2016, stands at 6377 cases, $14 \%$ higher than in the period prior to 2010 to 2014, in which 5547 cases were registered per year. Thus, between the years 2010 to 2016 there were a total of 41,321 suicides, the states with the highest rates being Chihuahua, Yucatán, Aguascalientes, Campeche and Colima (INEGI, 2019). The registered trend of suicide mortality in the country is on the rise, reaching worrying levels; Indeed, the data for the years 2015 and 2016, registered by the National Institute of Statistics and Geography (INEGI), show indicators of 6425 and 6370 cases, respectively. According to INEGI data, the trend of suicides in the country shows that men are the ones who most threaten their lives, occupy- 
ing up to $80.8 \%$ of the cases while women reach $19.5 \%$ of the total of suicide cases that occurred in 2016.

Among the pathologies associated with suicide, depression is found in the first place in most of the reported cases, followed by anxiety, bipolarity and schizophrenia, although terminal illnesses have also been the motivation to commit the suicidal act (Hernández-Bringas \& Flores-Arenales, 2011).

The importance of the evidence of a posthumous message helps to establish the emotions for which someone committed said act since it is the last contact they have with their reality, by leaving in writing the reasons and emotions that the person experiences moments before attempting against his life 10. It is likely that the subject does not have the necessary tools to overcome the frustration of a separation or a work or financial problem, reason why this study aims to delve further into locating the most frequent reasons for suicide in subjects living in Mexico City.

\section{Results}

- Gender frequency. In the total of reviewed cases with notes $(n=31)$, it was found that $10(32 \%)$ corresponded to women and $21(68 \%)$ corresponded to men. So, the proportion of women was 0.3225 whereas the proportion of men was 0.6774 . Applying the formula of the difference between proportions, a trust of 0.90 , and alpha 0.10 , the obtained proportion of men (36\%) surpasses women's (23\%), i.e., the percentage difference is $13 \%$. Therefore, the proportion is 2.1 men left a premortem note.

- Regarding their marital status, $60 \%$ of women were single whereas $38 \%$ of men were married; the proportion of singles is 0.3870 , whereas the proportion of free union is 0.3225 . When the formula of the difference between proportions was applied, it was found that $40 \%$ corresponded to singles and $27 \%$ corresponded to free union. So, there was a percentage difference of $13 \%$ meaning that the number of singles was higher than the number of free unions. Therefore, for each person in free union, there are 1.2 singles that left a note.

- Regarding the level of education, it was found that $40 \%$ of women went to high school, whereas $38 \%$ of men went to high school. Regarding bachelor's degrees, the percentage of women was $30 \%$ whereas men's was $24 \%$. So, the proportion of high school was 0.3870 and the proportion of bachelor's degree was 0.2580 . Once the formula of the difference between proportions is applied, the results showed that high school was the frequent level of education (46\%) followed by the bachelor's degree (20\%). In conclusion, the percentage difference is $26 \%$ of people that concluded high school is higher than people who finished a mayor. Moreover, for each person with a Bachelor's degree, 1.5 people finished high school.

- Regarding occupation, results showed that employees had a high percentage ( $48 \%$ men), whereas housewives had a percentage of $30 \%$. Policemen had $14 \%$, whereas policewomen had $20 \%$. So, the proportion was 0.3225 and po- 
lice officers proportion was 0.1612 . Once the difference between proportions formula was applied, it was shown that employees represent $52 \%$, whereas police officers represent $20 \%$. Therefore, the proportion difference is $32 \%$ concluding that the employee proportion is higher than the police officers proportion.

- Correlating the occupation with the level of education, it was found that people who finished high school and had a job represented 35\%, whereas people who finished a major and had a job represented $10 \%$. Nevertheless, $13 \%$ of the sample total was people who worked in a job related to his/her major. Once the difference between proportions was applied, $92 \%$ of people had a job whereas $31 \%$ of people have a bachelor's degree. So, the proportion was for every bachelor's degree, there were 4.8 people with an occupation.

- Regarding the receiver of the note, results showed that most of the posthumous notes had no receiver ( $40 \%$ women and $29 \%$ men). However, once the information was analyzed the results showed that a couple of the subject was in second place as the receiver (20\% women and $33 \%$ men); in third place, it was the parents the receiver ( $20 \%$ women and $19 \%$ men). So, the proportion for the couple is 0.2903 and for the parents is 0.1935 . Once the difference between proportions formula was applied, the obtained information showed that $46 \%$ is for the couple, whereas $27 \%$ is for the parents. The percentage difference was $19 \%$, concluding that the receiver proportion of the couple surpasses the proportion of parents. Furthermore, for each note sent to the parents, 1.5 notes are sent to the couple.

- The most frequent place of death was the bedroom (20\% women and 52\% men), followed by the living room ( $30 \%$ women and $5 \%$ men). The proportion of the bedroom was 0.4193 and of the living room was 0.1290 . Once the difference between proportions formula was applied, results showed that the bedroom represented $64 \%$, and the living room $6 \%$. So, the percentage difference was $58 \%$ concluding that the proportion of the bedroom was higher than the living room. So, for each death in the living room, there was 3.25 death in the bedroom.

- The main motivation for suicide was sentimental (45\% women and $52 \%$ men), followed by guilt ( $27 \%$ women and $5 \%$ men). The proportion of sentimental motivation was 0.5161 and guilt 0.1290 .

- Once the difference between proportions formula is applied, results showed that the main motivation was sentimental $(73 \%)$, whereas guilt was $4 \%$. The difference was $68 \%$ concluding that sentimental motivation is higher than guilt, and for each person that committed suicide because of guilt, 4 people committed it for sentimental causes.

- Regarding their background, depression was frequent (50\% women, $29 \%$ men) compared to the unhealthy. Results show $30 \%$ women and $26 \%$ men. So, the depression proportion was 0.4516 and the healthy subject proportion was 0.3548 . Once the difference between proportions formula was applied, 
results show that depression had $42 \%$ and the healthy had $22 \%$. The percentage difference was $19 \%$ concluding that depression surpasses the healthy, and for each healthy person, there were 1.2 people with a history depression.

- The month with the highest frequency in death, it was found that suicides increased during winter (38\% women and 60\% men) in January, and (60\% women and $40 \%$ men) in February. During summer and fall, women did not show any suicidal activity, whereas men activity increased in May, which is $100 \%$ of all the cases in that month.

- When the districts were analyzed, the district with the highest percentage was Iztapalapa ( $30 \%$ women and $24 \%$ men), followed by Cuauhtémoc ( $14 \%$ men).

\section{Results from the Second Phase of the Study Correspond to the Content Analysis of the Notes}

The results of the deictic analysis (tenses) in the 31 notes were the following:

- 24 out of the 31 analyzed notes were in present simple, in other words, $77 \%$ of the notes are related to statements meaning that they were aware of the act they were committed at the moment.

- Past simple in the analysis showed that 12 out of the 31 analyzed notes $32 \%$ of them are expressed in present simple.

The notes explicitly showed their mood state. Thus, it expressed that it was their own choice, as a matter of fact, one note explains very detailed all the steps of hanging, the time and the effect on the person. It also showed the distance between the knot and the rope. Note No 15.

\section{I feel "I feel an empty space in my chest. I have nothing to live for. Nothing}

- The analyzed notes show, very detailed, an emotional burden about specific situations that involve two people; most of the expressions were grievance. This discursive object corresponds an $80 \%$, and it is related to guilt or they blame someone: a relative, their father, their mother, their couple, or themselves. Note 10 .

\section{You don't love me enough for you don't accept my other part.}

- The frequency of appearance of the tenses in the notes was future simple $30 \%$ in the total of the analyzed notes.

- Regarding farewells-thankfulness, this relation is shown $20 \%$ in the analyzed notes.

- The frequency index analysis of the used words in the notes. 


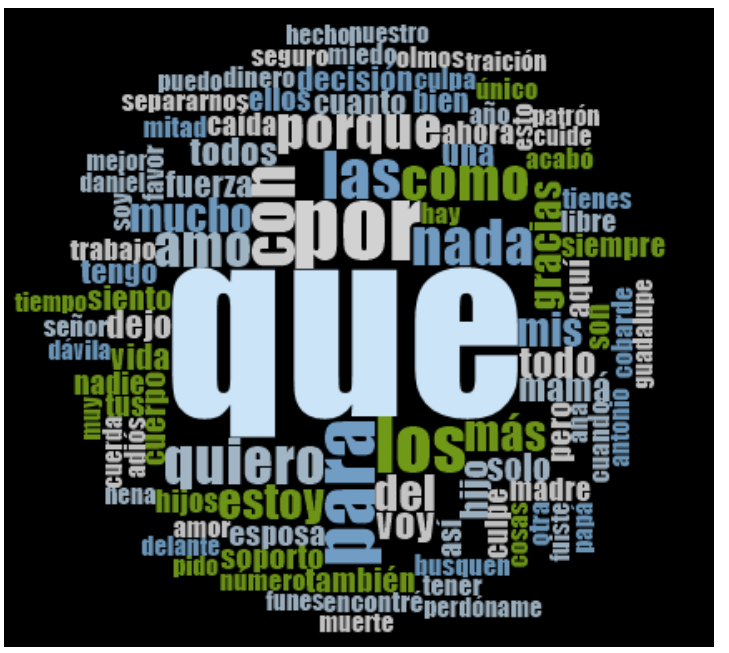

Figure 1. The figure shows in frequency order the number of times the words were used in the analyzed texts.

Men have the highest rate of suicides in comparison with women. Women's marital status was single, whereas men's marital status was married. The sentimental motivation, especially not being love, was determined as the main motivation in men, followed by guilt in women, and finally with a low percentage was work problems. It is important to mention that the most affected occupation is police officers regardless of sex. Economic causes were a constant factor among the posthumous notes.

Depression determines and increases the chances to commit suicide. An increase of suicides was found in the analyzed notes during winter (January and February); a decrease of suicides was found during summer. Iztapalapa was the district where there was an increase of suicides followed by Cuauhtémoc. It is noteworthy that those districts are known by their high insecurity levels within Mexico City.

Using the live $\mathrm{N}$ software in the frequential analysis of the words (Figure 1), I agree with the results of the text analysis, since it was found that guilt was one of the main motivations. There are some notes written a few days before the suicide because there were some specific instructions in those notes. In $77 \%$ of the notes, the subject wrote in present simple meaning that s/he was aware of and decided to commit suicide.

\section{Conclusion}

Men have a higher suicide rate compared to women; the marital status in the case of women was to be single while for men, their marital status was to be married. As for the main motivation, sentimental causes were determined, mainly heartbreak in the case of men and secondly, the feeling of guilt, mainly in the case of women. A lower percentage was found caused by work problems. A constant factor within the posthumous messages is the antecedent depression that conditions and increases the possibility that someone commits a suicidal 
act. The analyzed messages show that when there were increases in suicide by both genders, it was in the winter season in months like January and February, decreasing in the summer. And the highest increase in suicide reported by the mayor's office was in Iztapalapa, where there is a low social stratum, known for their high index of insecurity within Mexico City.

\section{Acknowledgements}

We acknowledge and thank the original source provided by the National Institute of Forensic Sciences (INCIFO) in Mexico City since it acknowledged that this kind of research must be supported by the institutions.

\section{Conflicts of Interest}

The authors declare no conflicts of interest regarding the publication of this paper.

\section{References}

Durkheim, E. (1995). El suicidio (p. 10). México: Coyoacán.

González, M. L. S. (2010). Discriminación, discurso y SIDA. Cuicuilco, 17, 43-60. http://www.scielo.org.mx/scielo.php?script=sci_arttext\&pid=S0185-1659201000020000 $4 \& \operatorname{lng}=\mathrm{es} \& \ln \mathrm{ln}=\mathrm{es}$

González, M. L. S. (2014). Modelos de Análisis lingüísticos aplicados al Discurso de la salud: Identidad Discurso y SIDA (pp. 159-209). Instituto Politécnico Nacional.

González, M. L. S. (2020). Design of an Expert System, Based on the Identification of Risk Factors Associated with Suicidal Ideation and Suicide Attempt. From Biochemical and Psycho-Social Analysis in University Students. Registry Secretariat for Research and Postgraduate Reg No IP: 20201503, Year 2020, Director of the Dra Marì de la Luz Sevilla Gonzàlez Project. Funded by the National Polytechnic Institute, México. (In Press)

Hernández-Bringas, H. H., \& Flores-Arenales, R. (2011). El suicidio en México. Papeles de Población, 17, 70-101.

Juárez, G. A. (2015). Specialty Thesis Forensic Medicine: Premortem Letter: The Last Speech of a Suicide by Means of Cluster Analysis. Mexico City National Polytechnic Institute: IPN.

National Statistics on suicide Prevention National Data (INEGI) (2019). Press Release No. 455/19 (p. 1, 9). 10 September 2019.

National Statistics on suicide Prevention National Data (INEGI) (2020). Press Release No. 422/20 (p. 1, 2). 8 September 2020.

Nely Rodríguez, D. (2019). Motivation for Suicide Expressed in Posthumous Messages in Mexico City. Forensic Medicine Thesis, Mexico City: National Polytechnic Institute.

OMS (World Health Organization) (2020). Suicide Prevention a Global Imperative. https://www.who.int/mental_health/suicide-prevention/es/

Román, S. J. (2020). Identification of Factors Linked to Suicide and Their Correlation with Psychosocial and Academic Variables in IPN Medicine Students. Mexico City: National Polytechnic Institute (IPN).

WHO (2020). Suicide Prevention: A Global Imperative. World Health Organization. https://www.who.int/mental_health/suicide-prevention/es/ 